\title{
Pufferfish mortality associated with novel polar marine toxins in Hawaii
}

\author{
Thierry M. Work ${ }^{1, *}$, Peter D. R. Moeller ${ }^{2}$, Kevin R. Beauchesne ${ }^{2}$, Julie Dagenais ${ }^{1}$, \\ Renee Breeden ${ }^{1}$, Robert Rameyer ${ }^{1}$, William J. Walsh ${ }^{3}$, Melanie Abecassis ${ }^{4}$, \\ Donald R. Kobayashi ${ }^{5}$, Carla Conway ${ }^{6}$, James Winton ${ }^{6}$ \\ ${ }^{1}$ US Geological Survey, National Wildlife Health Center-Honolulu Field Station, Honolulu, HI 96850, USA \\ ${ }^{2}$ National Oceanic and Atmospheric Administration, National Ocean Service, Charleston, SC 29412, USA \\ ${ }^{3}$ Hawaii Department of Land \& Natural Resources, Division of Aquatic Resources, Kailua-Kona, HI 96740-2721, USA \\ ${ }^{4}$ Joint Institute for Marine and Atmospheric Research, Honolulu, HI 96822, USA \\ ${ }^{5}$ National Oceanic and Atmospheric Administration, Pacific Islands Fisheries Science Center, Honolulu, HI 96818, USA \\ ${ }^{6}$ US Geological Survey, Western Fisheries Research Center, Seattle, WA 98115, USA
}

\begin{abstract}
Fish die-offs are important signals in tropical marine ecosystems. In 2010, a mass mortality of pufferfish in Hawaii (USA) was dominated by Arothron hispidus showing aberrant neurological behaviors. Using pathology, toxinology, and field surveys, we implicated a series of novel, polar, marine toxins as a likely cause of this mass mortality. Our findings are striking in that (1) a marine toxin was associated with a kill of a fish species that is itself toxic; (2) we provide a plausible mechanism to explain clinical signs of affected fish; and (3) this epizootic likely depleted puffer populations. Whilst our data are compelling, we did not synthesize the toxin de novo, and we were unable to categorically prove that the polar toxins caused mortality or that they were metabolites of an undefined parent compound. However, our approach does provide a template for marine fish kill investigations associated with marine toxins and inherent limitations of existing methods. Our study also highlights the need for more rapid and cost-effective tools to identify new marine toxins, particularly small, highly polar molecules.
\end{abstract}

KEY WORDS: Dereplication $\cdot$ Pathology $\cdot$ Tetraodontidae $\cdot$ Toxinology $\cdot$ Virology

\section{INTRODUCTION}

Mass mortalities of marine fish are poorly documented, with more events published in the press than in the scientific literature (La \& Cooke 2011). Investigating and understanding causes of mass mortalities of marine fish are important, because they are honest signals of environmental perturbations (Scheffer et al. 2009) that could damage populations of native species or, in some cases, impact public health. Causes of fish kills include hyposalinity (Bennett 1985), extremes in temperature (Bohnsack 1983), infectious agents (Glibert et al. 2002), and pollution (Thronson \& Quigg 2008). Fish kills caused by infec- tious agents usually affect a limited number of host species, for example the herpesvirus associated with a massive mortality of pilchards in eastern Australia (Whittington et al. 1997). Other causes, such as fish kills associated with toxic algal blooms, are usually non-selective and affect multiple species (Pinheiro et al. 2010), with some toxins bioaccumulating in the human food chain (Brusle 1995). Documenting new natural compounds associated with fish mortalities is rare, and most cases are identified based simply on temporal co-occurring blooms of algae known to produce well characterized toxins (Brusle 1995).

Documenting fish kills in tropical coral reef ecosystems poses particular challenges. Tropical reef fish

(1) W. J. Walsh, M. Abecassis and (outside the USA) the US Government 2017. Open Access under Creative Commons by Attribution Licence. Use, distribution and reproduction are unrestricted. Authors and original publication must be credited. 
that are sick or dying often simply disappear and are thus rarely noticed (Aldenhoven 1986), and diagnostic labs are usually informed (if at all) of the kills days or weeks after the event has peaked, whereupon specimens are often decomposed in the tropical heat. Fish kill events in remote islands may not be reported or observed, and in many Pacific islands, there is no capacity to investigate fish kills. In the tropics, as elsewhere, reports of fish kills generally involve anecdotal estimates of numbers of fish and perhaps species affected, concomitant with various speculations on potential causes. Indeed, a plea has been made for greater involvement of animal disease expertise in fish kill investigations (La \& Cooke 2011).

In 2010, an unusual mortality event limited to mainly stripebelly puffers Arothron hispidus with a minority of spotted puffers A. meleagris and porcupine fish Diodon hystrix occurred throughout the Hawaiian Islands. We evaluated clinical signs, spatial and temporal distribution, pathology, toxinology, and potential demographic effects associated with the mortality to show that a suite of heretofore undescribed polar marine toxins were the likely cause. Our findings are unusual, because we show evidence of a toxicosis affecting only a targeted group of fish (Tetraodontidae), and our approach allowed us to disentangle a polar toxin from a species of fish that is itself inherently toxic (Helfrich 1963). This study should provide a useful template to investigate other fish kill events in tropical marine ecosystems.

\section{MATERIALS AND METHODS}

To document the geographic and temporal extent of the mortality, we called out to the public to report sick or moribund fish and kept a log of phone or email reports. Moribund fish from neighbor islands (Maui, Kauai, Maui, Molokai, and the island of Hawaii) were shipped on ice by air freight to Honolulu, Hawaii, for examination the following day.

To assess potential demographic effects of the mortality, count data for puffer fish were obtained from long-term survey data collected for the West Hawaii Aquarium Project (Williams et al. 2009). Since 1999, this project has systematically surveyed the same 23 sites on the west coast of the island of Hawaii 4 to 6 times $\mathrm{yr}^{-1}$ and thus has the most complete long-term demographic data for reef fish in the Hawaiian Islands.

Necropsies were done on 125 moribund puffers including 120 Arothron hispidus, 2 Diodon hystrix, 2 A. meleagris, and 1 Canthigaster jactator to determine cause of death and were limited to moribund fish to minimize post-mortem artifacts on histopathology secondary to decomposition (Wolf et al. 2015). Moribund fish from Oahu were humanely euthanized with an overdose of tricaine methanesulfonate (MS222). Fish were weighed (nearest 0.1 g), measured (fork length to nearest $0.1 \mathrm{~cm}$ ), and given a complete external and internal exam. A subset of fish was bled, and blood smears were made and stained with Wright's stain for microscopic examination. Terminology for the description of red cell morphology followed that described elsewhere (Jain 1986). Representative tissues including skin, skeletal muscle, brain, eye, gas bladder, liver, gonad, spleen, cranial and caudal kidney, and gastrointestinal tract were collected, and 1 or 2 random slices from each organ were fixed in $10 \%$ neutral buffered formalin, embedded in paraffin, sectioned at $5 \mu \mathrm{m}$, and stained with hematoxylin and eosin. All tissue sections collected in formalin were examined on light microscopy. Separately, the same set of organs were frozen $\left(-20^{\circ} \mathrm{C}\right)$. Gender was determined by examination of gonads grossly or on histology. When available, stomach contents were grossly classified as corals, crustaceans, coralline algae, or unknown.

For virus isolation attempts, kidneys from $A$. hispidus collected on 4 sampling dates were frozen and shipped on dry ice to the USGS Western Fisheries Research Center (Seattle, WA). Tissues were thawed, homogenized, clarified, and $100 \mu$ aliquots inoculated onto $25 \mathrm{~cm}^{2}$ flasks containing monolayer cultures of the following fish cell lines: chinook salmon embryo (CHSE-214; ATCC CRL-1681), rainbow trout gonad (RTG-2; ATCC CCL-65), bluegill fry (BF-2; ATCC CCL-91), brown bullhead (BB; ATCC CCL59), fathead minnow (FHM; ATCC CCL-42), and epithelioma papulosum cyprini (EPC; ATCC CRL-2872). Additionally, gill, swim bladder, and kidney homogenates were inoculated on green turtle embryo fibroblasts (Moore et al. 1997) and terrapin heart cells (ATCC CCL-50) at the USGS National Wildlife Health Center, Honolulu Field Station (Honolulu, $\mathrm{HI})$. Cells were incubated at $30^{\circ} \mathrm{C}$, observed for cytopathic effect (CPE) for $21 \mathrm{~d}$, passed, and observed for an additional $14 \mathrm{~d}$. Liver, kidney, gill, and optic nerve tissues from 2 additional puffers were placed in RNAlater® and shipped to the Western Fisheries Research Center. Total RNA was extracted, pooled, and used as template in reverse transcription-PCR assay for nervous necrosis virus (OIE 2006).

For electron microscopy to detect viruses, samples of liver and gills from 2 normal and 3 diseased $A$. hispidus were fixed in Trump's fixative (McDowell \& Trump 1976), rinsed in 0.1 M Sorenson's phosphate buffer 
(pH 7.40), post-fixed in $1 \%$ osmium tetroxide, and then stained en bloc with $1 \%$ aqueous uranyl acetate. Ultrathin (80-90 nm) epoxy resin-embedded tissues were transferred to copper grids, stained with $2 \%$ aqueous uranyl acetate followed by $0.4 \%$ lead citrate, then sent to the University of Montana on-line electron microscopy facility where they were examined using a Hitachi H-7100 transmission electron microscope via the PCI Collaboration Microscopy System.

To identify potential marine toxins associated with this mortality, livers from freshly dead puffers were frozen $\left(-20^{\circ} \mathrm{C}\right)$ and shipped on dry ice $\left(-70^{\circ} \mathrm{C}\right)$ to the Emerging Toxins program located in the Hollings Marine Laboratory (Charleston, SC). Livers from $3 \mathrm{~A}$. hispidus collected from Palmyra Atoll, a region in the equatorial North Pacific where no unusual mortalities of fish were observed, served as controls. Livers were pulverized in a cryomill $\left(-80^{\circ} \mathrm{C}\right)$ prior to lyophilization. The residual powder generated for each individual liver was taken through an eluotropic extraction process with solvents of increasing polarity in the following order: hexanes, ethyl acetate (EtOAc), methanol $(\mathrm{MeOH})$, and water $\left(\mathrm{H}_{2} \mathrm{O}\right)$. Cell lines reporting ion channel blocking activity were used to test extracts (Pierce \& Kirkpatrick 2001). Aliquots $(4 \mu \mathrm{l})$ of extract were inoculated on a Neuro 2A (mouse neuronal) cell line, a GH4C1 (rat pituitary) cell line, and an MCF7 (human breast cancer cell line) to assess activity. As the bioactive components shared the same mass spectral fingerprinting, all active aqueous and methanolic extracts were combined and reduced in volume under dry nitrogen using a turbo-evaporator.

High pressure liquid chromatography (HPLC) purifications were carried out on an Agilent 1100 model HPLC equipped with photo-diode array and fraction collector. The deeply colored dark brown/orange residual material from the bioactive extracts was readily soluble in $2 \mathrm{ml}$ of water. This solution was syringefiltered through a Millipore high performance filter (HPF) Milex-HV glass fiber $0.45 \mu \mathrm{m}$ filter prior to injection $(25 \mu \mathrm{l})$ into the HPLC mounted with 2 endto-end coupled $250 \times 4.6 \mathrm{~mm}$ columns packed with Luna C18 reverse phase media $(3 \mu \mathrm{m})$ used in efforts to maximize resolution. Chromatography was carried out at $35^{\circ} \mathrm{C}$ at a flow rate of $0.4 \mathrm{ml} \mathrm{min}{ }^{-1}$ with realtime photo-diode array (PDA) monitoring at 190 to $400 \mathrm{~nm}$ and fractions collected each minute for a total of 60 min with a 20 min recondition time. $\mathrm{H}_{2} \mathrm{O}+0.1 \%$ formic acid (A) was used as the loading solvent, followed by an elution scheme using acetonitrile (ACN) $+0.1 \%$ formic acid (B) with the following protocol: Hold A $(99 \%)+$ B (1\%) for 5 min followed by a linear gradient over the remaining 55 min to $99 \%$ B. Fractions were collected at 1 min intervals.

Fractions were assayed against Neuro 2A cells, with active fractions again combined, filtered as above, and dried. The sample was re-solubilized in $2 \mathrm{ml} \mathrm{H} \mathrm{H}_{2} \mathrm{O}$, and $50 \mu \mathrm{l}$ were loaded onto 2 coupled Atlantis T3 columns designed for use with highly polar analytes. Purifications were operated at $45^{\circ} \mathrm{C}$ at $1 \mathrm{ml} \mathrm{min} \mathrm{mith}^{-1}$ weal-time monitoring at 210 and $254 \mathrm{~nm}$ and $1 \mathrm{~min}$ fractions collected; stop time: 65 min with 20 min recondition time. Loading solvent was $\mathrm{H}_{2} \mathrm{O}(\mathrm{A})$ and elution solvent was ACN (B) with the following protocol: Hold B (100\%) 6 min followed by a linear gradient to the endpoint A (65\%) B (35\%) over $54 \mathrm{~min}$, and this final concentration held for 5 min to ensure complete elution of chemical analytes. Active fractions were combined, taken to dryness under a stream of dry $\mathrm{N}_{2}$ gas and then lyophilized for $24 \mathrm{~h}$ prior to structural analysis.

Nuclear magnetic resonance (NMR) was done on a Bruker DMX 500 and a Bruker $800 \mathrm{MHz}$ instrument equipped with a cryoprobe optimized for ${ }^{1} \mathrm{H}$ and ${ }^{13} \mathrm{C}$. Mass spectrometry was carried out using the following: Agilent 1100 Purification Series LC/MSD, WATERS HPLC system (WATERS 2767 Sample Manager), 1525 Binary Pump, 510 pump, WATERS 2996 PDA, and a WATERS ZQ Single Quadrupole Mass Detector (MS setting in Fig. S1 in the Supplement at www.int-res.com/articles/suppl/d123p087_supp.pdf)

\section{Environmental drivers}

To explore potential environmental drivers of this epizootic, we analyzed satellite-derived weekly sea surface temperature (SST) data from NOAA's GeoPolar blended $5 \mathrm{~km}$ product, and chlorophyll a (chl a) data from NASA's MODIS Aqua between 2002 and 2015 . Both data sets were regridded to a $0.05^{\circ}$ resolution and are available from NOAA Ocean Watch http://oceanwatch.pifsc.noaa.gov/thredds/catalog.html. We used MODIS Aqua data from the latest NASA reprocessing (June 2015). High-resolution (3.7 km) base bathymetry (Smith Sandwell) was interpolated to lower-resolution SST or chl a grids. Pixels deeper than $1000 \mathrm{~m}$ were masked to examine nearshore oceanographic conditions for the main Hawaiian Islands. The $1000 \mathrm{~m}$ is obviously excessive with respect to delineating puffer habitat, but was a necessary compromise given the spatial resolution of the data products and the steep bathymetry near many shorelines in the main Hawaiian Islands. Mean annual SST and chl $a$ were plotted, as was mean SST and chl a by 
month for each year, and plots were examined for patterns particular to the outbreak period (June to October 2010).

\section{Data}

Length of males versus females was compared using $t$-test after checking for equal variance. Body condition index (BCI) was calculated as weight / fork length ${ }^{3}$ (Le Cren 1951) and used as an index of nutritional condition. To compare BCI of fish from this epizootic to apparently normal puffers, we plugged in the length of Hawaii puffers to a linear equation relating length and weight of apparently normal $A$. hispidus in New Caledonia (Letourneur et al. 1998). Mean BCI calculated from the 2 formulas was then compared with a $t$-test. To identify the compounds identified on toxinology, we searched available liter- ature along with the following online databases: ChemSpider, PubChem, and CAS/SciFinder (Gaudencio \& Pereira 2015). We also looked at back issues of Natural Product Reports, a journal dedicated to compiling annual lists of newly discovered marine toxins from 2000 to 2015. Oceanographic analyses and statistical analyses were done with R (R Development Core Team 2011).

\section{RESULTS}

Puffers were found either dead on the beach or in the ocean puffed up and floating unable to submerge. In some cases, puffers were found in pairs with 1 animal biting and holding another. Occasional reports of puffers acting aggressively towards each other were received (Fig. 1), and in 1 instance, a puffer was recorded actively attacking snorkelers in
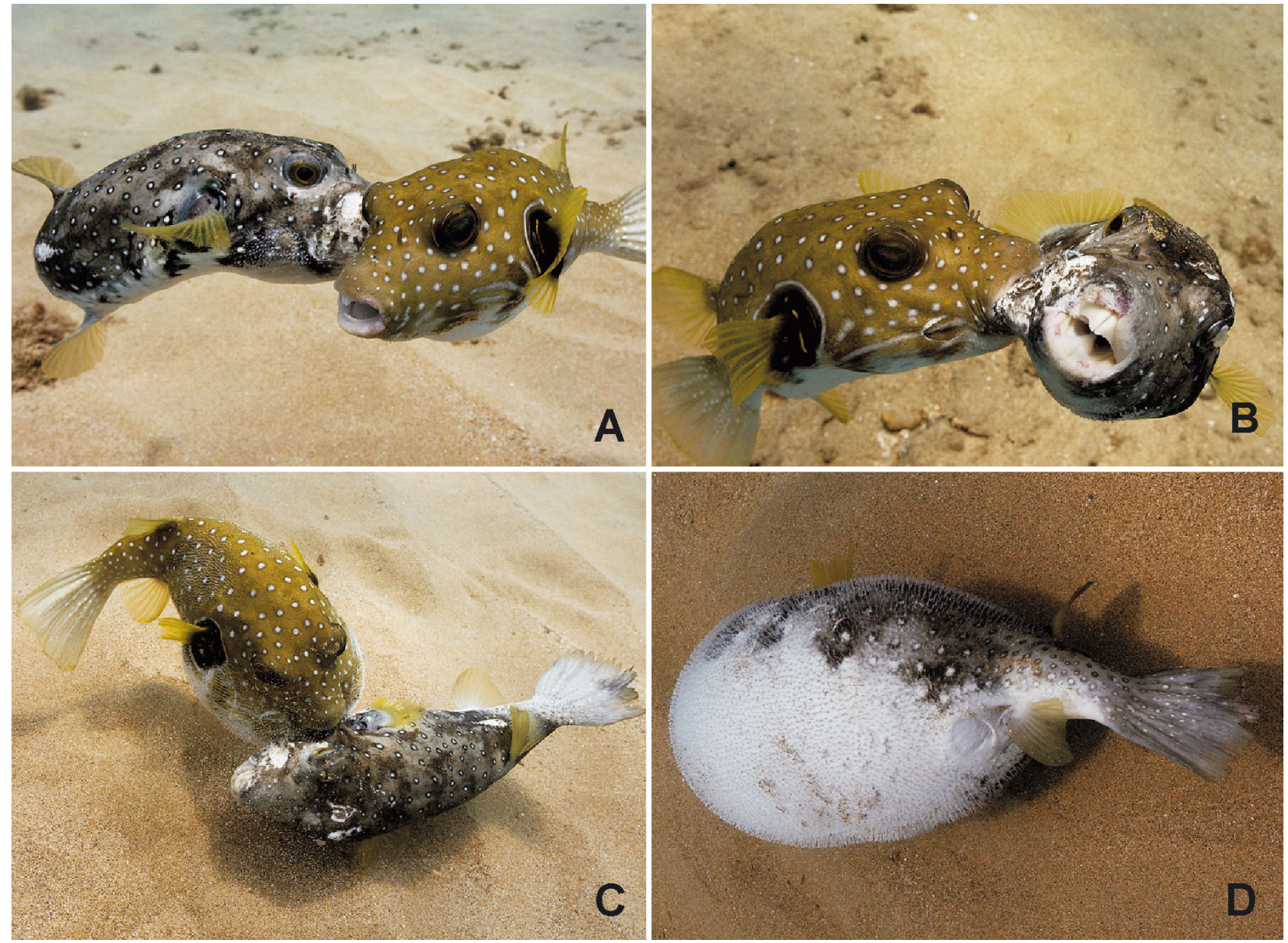

Fig. 1. Two Arothron hispidus showing abnormal behaviors. (A) Grey morph attacking green morph. Note severe white skin lacerations on the right side of the mouth of the grey morph. (B) Green morph attacking grey morph. (C) Green morph presses attack as it begins puffing. (D) Grey morph upside down, puffed, and immobile; this animal later deflated and resumed swimming. Photos $@$ Don McLeish (used by permission) 

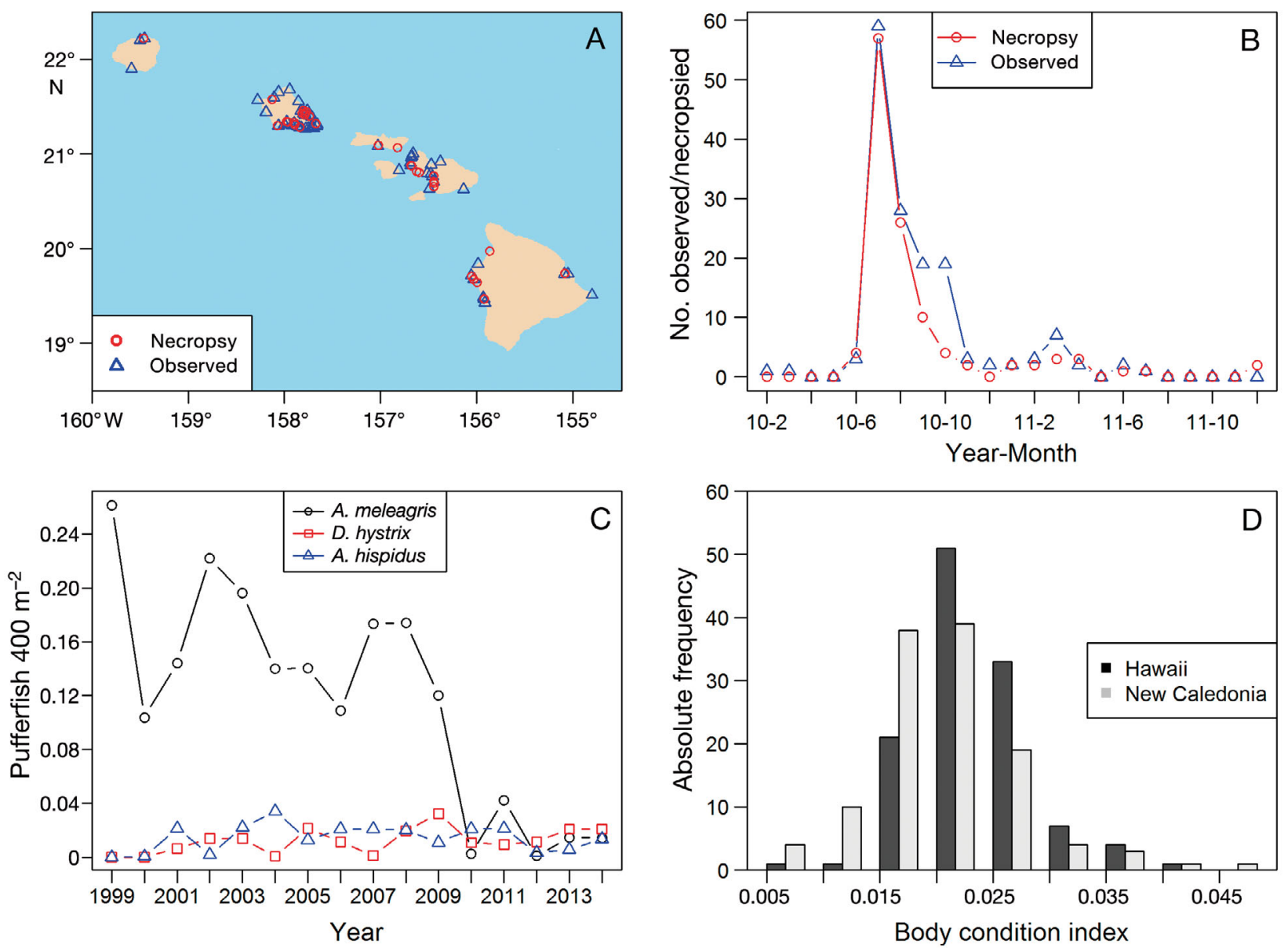

Fig. 2. Sick and dying puffers (Arothron hispidus, A. meleagris, and Diodon hystrix) were found throughout Hawaii in good body condition. (A) Location in the main Hawaiian Islands where puffers were observed dying or collected for necropsy. (B) Time line of numbers of puffers observed by the public or submitted for necropsy by year-month. (C) Counts of puffers on transects from western Hawaii over time. (D) Frequency distribution of body condition index of puffers from Hawaii and New Caledonia as comparison

the water. Interviews with snorkelers and local fishermen suggested that these behaviors were unusual. Observations of normal Arothron hispidus in the field (T. M. Work \& W. J. Walsh, pers. obs.) reveal them to be mostly solitary animals seldom seen interacting with other fish. Affected fish held temporarily in aquaria were unable to maintain neutral buoyancy and often struggled to remain submerged.

We received 159 reports from the public describing sick, dying, or dead puffers from all the main Hawaiian Islands (Kauai, Oahu, Maui, Molokai, Lanai, Kahoolawe, and Hawaii; Fig. 2A). Reports and recoveries of stranded fish peaked between June and October 2010 (Fig. 2B). Populations of A. meleagris at transects on the west coast of the island of Hawaii declined precipitously starting in 2009 and remained low from 2010 onwards, whereas no evident change was seen for Diodon hystrix or A. hispidus (Fig. 2C).
Necropsy findings focus on $A$. hispidus that had the largest sample size. Necropsied puffers originated mainly from Oahu and Maui, and females predominated (Table S1 in the Supplement). Mean ( \pm SD) length of males $(25.3 \pm 7.3 \mathrm{~cm} ; \mathrm{n}=31)$ did not differ significantly from females $(27.2 \pm 9.6 \mathrm{~cm} ; \mathrm{n}=71)$. Weight and length were significantly $(p<0.05)$ related with 112/120 (93\%) puffers being less than $40 \mathrm{~cm}$ fork length. Puffers from Hawaii were mostly in good body condition, and mean $\pm \mathrm{SD}, 95 \% \mathrm{CI} B C I$ of puffers from Hawaii $(0.024 \pm 0.005 ; 0.023-0.025)$ was significantly $(t=3.9, \mathrm{df}=236, \mathrm{p}=0.0001)$ greater than published for normal individuals of $A$. hispidus (Letourneur et al. 1998) from New Caledonia (0.022 \pm 0.005; 0.0224-0.0225; Fig. 2D), the only available data published for this species.

Externally, the most common gross findings were inflation of the stomach and variable numbers of 

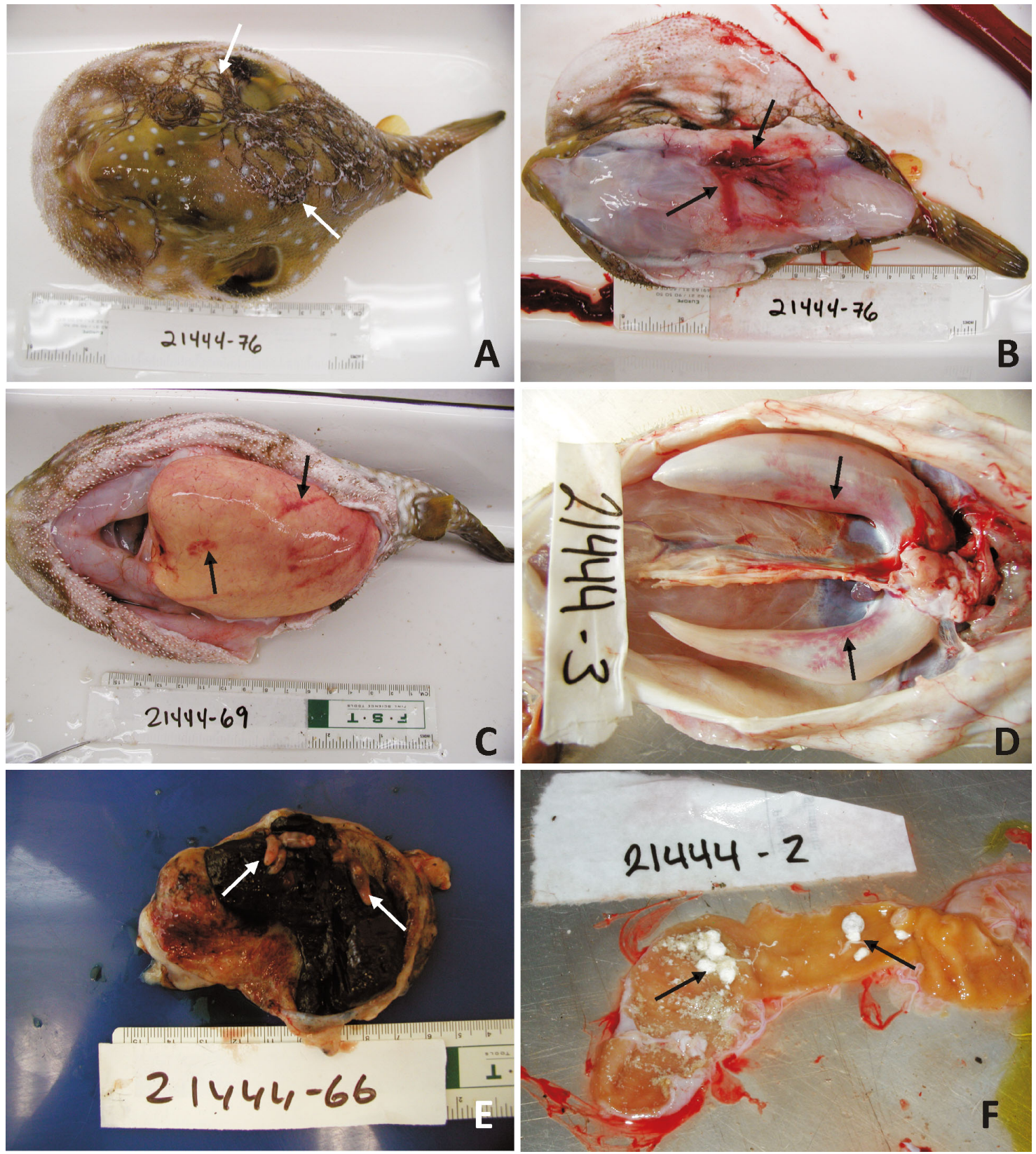

Fig. 3. Gross necropsy of Arothron hispidus. (A) Puffed fish with multiple circular scars on skin of dorsum (arrows). (B) Subcutaneous hemorrhage and edema of dorsum (arrows). (C) Massively enlarged orange liver with suffusive hemorrhages (arrows). (D) Inflated gas bladder with suffusive hemorrhages (arrows). (E) Cut surface gas bladder with trematode infection; note thickened gas bladder wall, masses of black tarry material, and helminths (arrows). (F) Clumps of unidentified flocculent white material in lumen of gut (arrows)

semi-circular cuts on the skin or lips (Table $\mathrm{S} 2$ in the Supplement, Fig. 3A). Varying degrees of accompanying subcutaneous bruising, edema, or emphysema (Fig. 3B) were seen in 34 fish. Internally, gross lesions were most often seen in the liver and gas bladder (Table S2). Grossly, the liver was markedly enlarged, and had a pale tan-orange-yellow discoloration with suffusive hemorrhages, and the gall bladder was distended by clear orange-yellow bile (Fig. 3C). Gas bladders were markedly distended with air with varying degrees of suffusive hemorrhage (Fig. 3D). Fifteen fish had thickened gas bladder walls and lumina filled with black tarry material and large trematodes (Fig. 3E). Gills most commonly had excessive 
mucus production occasionally laced with sediment deposition. Other less common gross lesions included gas or frank hemorrhage in the abdomen, sunken or cloudy eyes, or prolapsed cloaca. Thirty-one fish had grossly visible gut contents comprising $31 \%$ crustaceans, $28 \%$ unidentified friable white material (Fig. 3F), 8\% each algae, corals, and mollusks, 6\% urchins, $3 \%$ each plastic, sediment, or sponge, and $2 \%$ terrestrial plant material.

Of 1529 organs examined histologically, lesions were most often seen in the liver, spleen, gill, and kidney (Table S3 in the Supplement). A complete list of quantified histological findings by tissue is presented in Table S4 in the Supplement, representative normal histology is shown in Fig. S2, and significant findings are summarized here. Putative initial liver lesions manifested as vacuolation of hepatocytes in periportal zones associated with hemorrhage (Fig. 4A) or coagulation necrosis (Fig. 4B). In later stages, liver architecture was mostly effaced by coalescing vacuoles disrupting cell membranes (Fig. 4C) that differed markedly from normal liver (Fig. 4D). Gills manifested necrosis, lamellar collapse with sloughing and necrosis of lamellar epithelium (Fig. 4E), and occasional presence of rosettes within secondary arches (Fig. 4F). Occasional aggregates of Myxosporea were seen within the cartilage at the base of primary gill arches sometimes associated with eosinophilic debris.

Acute diffuse perirenal hemorrhage was common in kidneys (Fig. 5A), and less commonly, we saw renal tubular necrosis and depletion of hematopoietic elements within cranial kidney (Fig. 5B). Common changes in gas bladder included intramural hemorrhage, with vacuolation and necrosis of gas gland cells (Fig. 5C). Within gas bladders parasitized by trematodes, the wall was markedly thickened with deposition of granular brown pigment and trematode eggs (Fig. 5D). The brain had occasional vascular congestion, gliosis, and neuronal necrosis. Intestines had multiple foci of necrosis and chronic inflammation with encysted metazoans within smooth muscle walls. The eye had periocular hemorrhage and engorgement of rete mirabile. Rhabdomyolysis was common in skeletal muscle. Lesions were uncommon in adrenals, urinary bladder, heart, and gonads (Table S4). Of 67 blood smears, 28 showed red cells manifesting poikilocytosis (Fig. 5E) or matchstick forms (Fig. 5F).

No viruses were detected by cell culture or RTPCR. On electron microscopy, liver lesions showed numerous individual to coalescing vacuoles in hepatocytes and the disintegration of the vascular endo- thelium. No viral-like particles, bacteria, or other micro-organisms were observed in any tissues.

Hexanes and EtOAc extracts from livers of affected puffers generated light toxic activity that was subsequently shown via nuclear magnetic resonance (NMR) and mass spectrometry (MS) to arise from fatty acids. No other class of bioactive compounds was found in these extracts. The methanolic extracts, of $9 / 16$ livers however, proved to be very cytotoxic to the Neuro 2A cell line. Water extracts were weakly active but MS and NMR analysis demonstrated identical chemical components as those found in the $\mathrm{MeOH}$ extracts. Chromatography, NMR, MS, and cell assay guided fractionation revealed presence of several polar toxins from the liver with one particular toxin predominating (Fig. 6). These toxins exhibited highly polar characteristics, existed in very low abundance and proved very difficult to separate on HPLC. There was no significant evidence of tetrodotoxin (TTX) or saxitoxin (STX) in the samples analyzed. No toxic activity was seen in cell lines from liver extracts originating from the 3 fish collected at the control site in Palmyra.

The outbreak occurred during a year where SST and chl a levels were generally lower compared to other years and near the end of a continuous decline of SST over 8 yr. The epizootic occurred in months (June to October) where SSTs were increasing and $\mathrm{chl}$ a levels were at annual lows; however, chl a levels were higher than normal in months preceding the epizootic (Fig. S3).

\section{DISCUSSION}

Aggregate field and pathology observations indicated an acute toxicosis as the cause of this epizootic based on the following. (1) Fish were in generally good body condition with stomach contents indicating rapid death. (2) Gross and microscopic findings were acute, and histology of the liver failed to reveal changes such as fibrosis that are more indicative of chronic insults (Brockes \& Kumar 2008). (3) Light and electron microscopy of the liver indicated changes typical of toxic disease. For instance, a hallmark of marine algae toxicosis in fish is vacuolar change in the liver (Brusle 1995). Deformed red cells were also indicative of toxicosis, because this change is common in poisoned fish (Katalay \& Parlak 2004, Clauss et al. 2008). Histology and microbiology did not reveal infectious agents, and only a minority of fish $(12 \%)$ had bladder trematodes, which were considered incidental findings. 


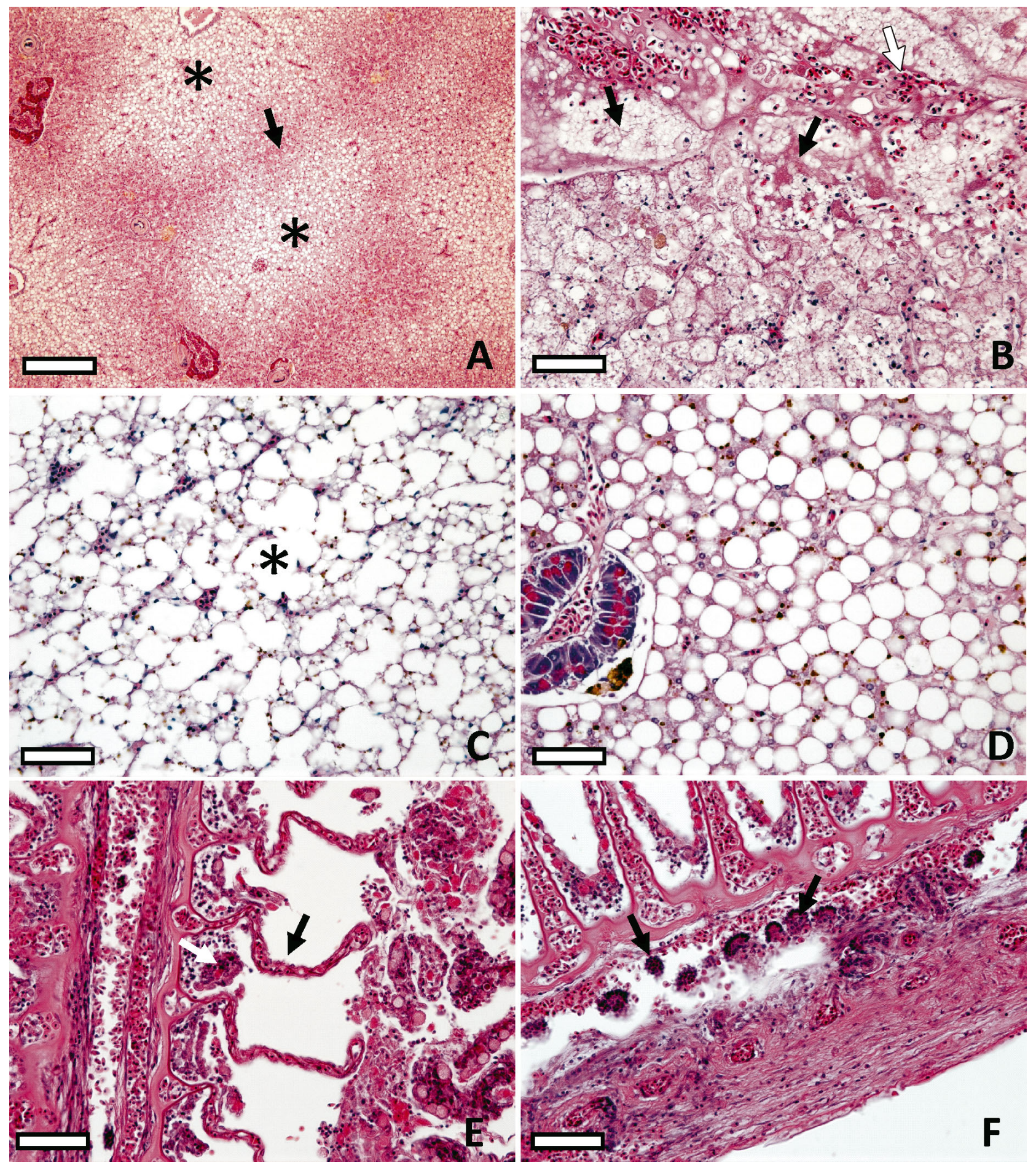

Fig. 4. Histology of gill and liver in Arothron hispidus. (A) Putative early liver lesions showing vacuolation of hepatocytes centered around portal areas (asterisks) bordered by hemorrhage and necrosis (arrow). (B) Close up of liver hemorrhage (white arrow) and liquefaction necrosis (black arrows). (C) Late-stage liver with hepatocytes distended with numerous vacuoles many of which are coalescing and associated with ruptured cell membranes (asterisk) and pyknotic nuclei. (D) Normal puffer liver as comparison; note uniform round intracytoplasmic fat vacuoles. (E) Gill with collapsed secondary lamellae (black arrow) and sloughing and necrosis of lamellar epithelium (white arrow). (F) Primary lamellae of gill with rosettes (black arrows). Scale bars $=(A) 200 \mu \mathrm{m},(\mathrm{D}-\mathrm{F}) 50 \mu \mathrm{m}$ 


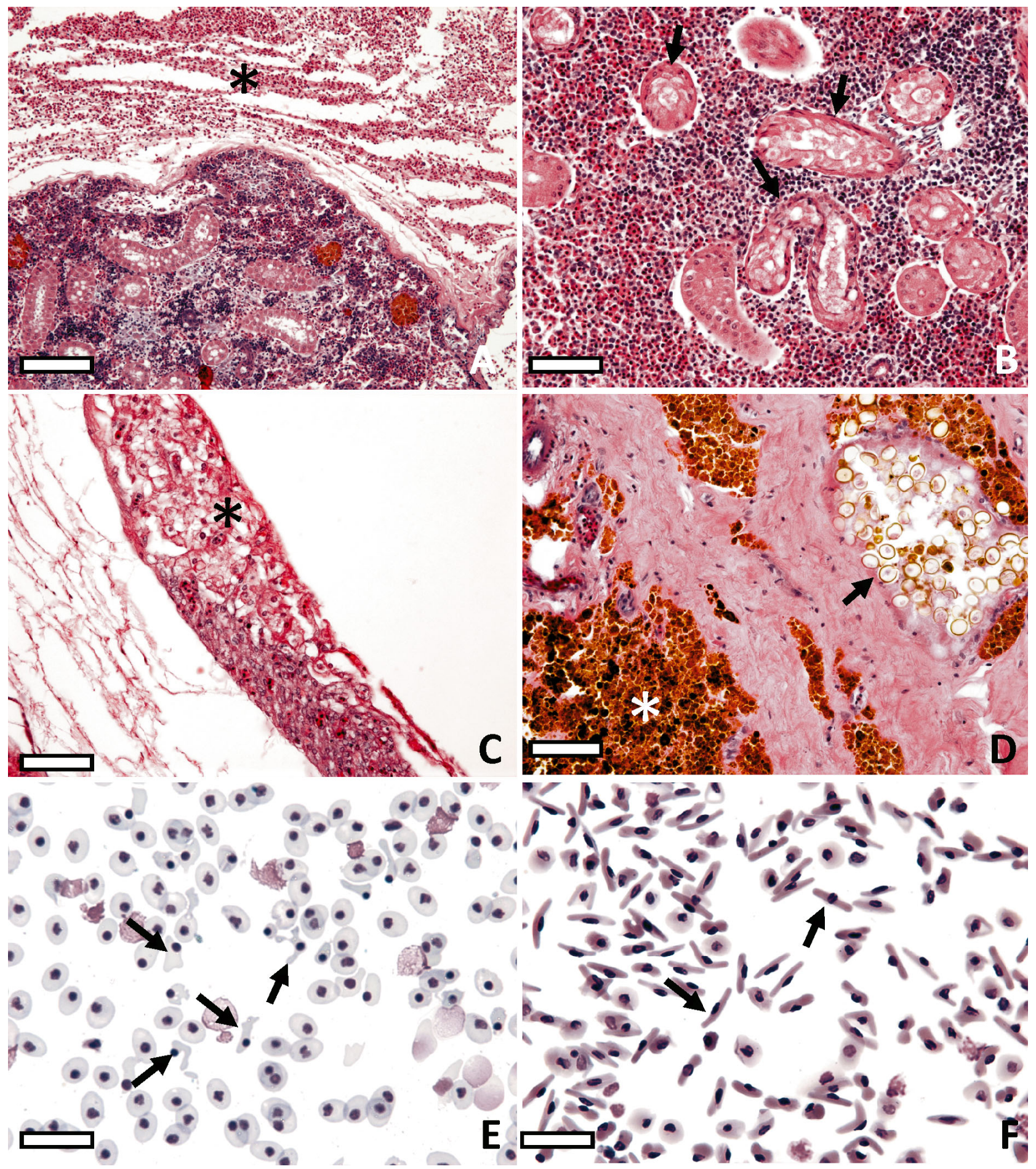

Fig. 5. Histology of kidney, gas bladder, and hematology of Arothron hispidus. (A) Severe diffuse perirenal hemorrhage (asterisk) in caudal kidney. (B) Acute renal tubular necrosis in caudal kidney; note proximal tubules manifesting cytoplasmic hypereosinophilia and pyknosis (arrows). (C) Necrotic gas gland (asterisk) in gas bladder. (D) Gas bladder parasitized by trematodes; note pigment deposition within thickened wall (asterisk) and trematode ova (arrow). (E) Blood smear with pleomorphic poikilocytes (arrows) contrasted with normal red cells that are ovoid to elliptical. (F) Matchstick form blood cells (arrows); note almost complete absence of normal red cells. Scale bars = (A) $100 \mu \mathrm{m},(B-D) 50 \mu \mathrm{m},(\mathrm{E}, \mathrm{F}) 20 \mu \mathrm{m}$ 


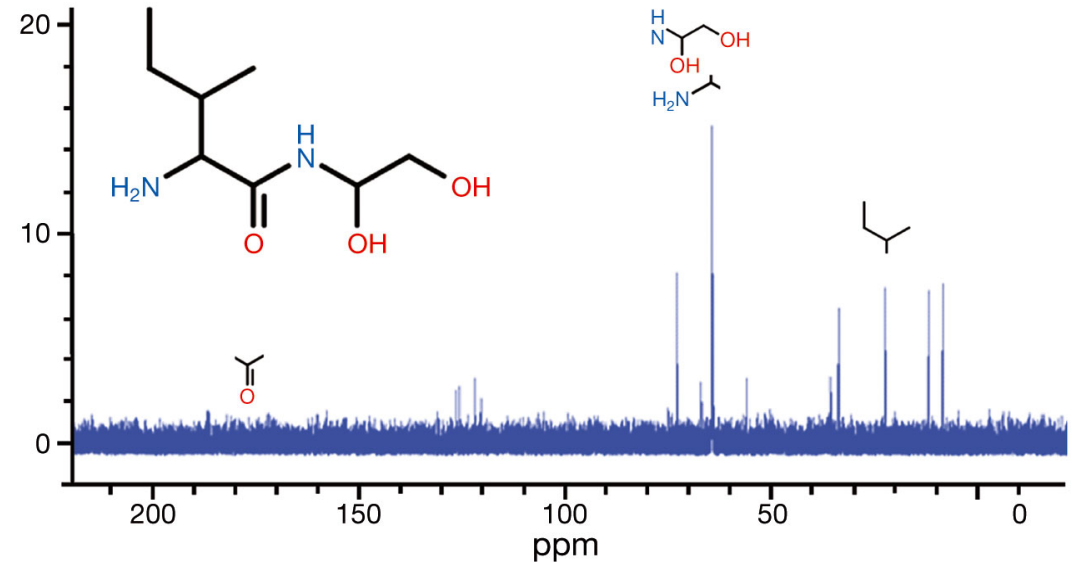

Fig. $6 .{ }^{13} \mathrm{C}$-nuclear magnetic resonance (NMR) spectrum of extract containing the dominant putative causative toxin associated with puffer die off along with structure and fragments of molecules corresponding to peaks in NMR trace. Though still a mixture, ${ }^{13} \mathrm{C}$ and ${ }^{1} \mathrm{H}$ signals are easily resolved in heteronuclear multiple bond correlation (not shown). No label on y-axis is by convention for NMR spectra

The pathology gives some clues as to pathogenesis of the toxicosis and clinical signs seen in puffers. That the liver was the most commonly affected organ suggests it was the initial site of insult from the toxin. Hyperinflated gas bladders were the second most common gross pathology finding, and excessive buoyancy might explain why affected fish struggled to remain submerged. As blood passes through the gas gland, $\mathrm{pH}$ decreases as $\mathrm{O}_{2}$ is released from the gland into the bladder lumen, whereupon exiting blood becomes acidic where it goes to the liver for metabolism (Fänge 1983). We suspect that vacuolar change and necrosis of hepatocytes impeded the liver's ability to metabolize excess lactic acid. Unlike fish species with a physostomous gas bladder that opens to the gut, puffers have a physoclistous, or closed, gas bladder, so the only way gas can escape is through diffusion (Chanet et al. 2014). Metabolic acidosis likely exacerbated gas production leading to hyperinflation of the gas bladder and subsequent trauma as evidenced by some fish with ruptured gas bladders. Proximity of the gas bladder to caudal kidneys likely led to pericapsular hemorrhage in those organs. Hyperinflation of the gas bladder led to excessive buoyancy resulting in struggling to remain submerged, thus creating a vicious cycle exacerbating the acidosis and leading to contraction of the spleen where this occurs within $5 \mathrm{~min}$ of exercise in fish (Yamamoto 1988). This would then explain depletion of red pulp that was the dominant histologic lesion in the spleen. Stress of trying to maintain submerged led to puffing (pumping of water to inflate the stomach), an energyintensive process that also likely contributed to metabolic acidosis (Brainerd 1994).
The changes in the gill (sloughing of epithelium, lamellar collapse) were more difficult to interpret. We saw pufferfish burrowed in the sand or wedged between rocks or urchins presumably in attempts to remain submerged, and sediment damage might have contributed to gill pathology. Epithelial changes in the gills can be caused by a variety of insults (Velmurugan et al. 2009), and toxins can cause lamellar collapse (Mallatt 1985). We are less sure of the origin of rosettes within primary lamellae, as this pathology has not been described before in finfish. Changes in the gill were not post-mortem decomposition or fixation artefacts (Wolf et al. 2015), because lesions were seen in humanely euthanized fish and not in all fish. The numerous bite marks on affected fish were secondary to the intraspecific aggression. Whether this abnormal behavior was caused by the putative toxin or was secondary to metabolic disorders could not be determined; however, that this behavior was abnormal is beyond dispute, because Arothron hispidus are normally solitary animals (Hobson 1974). The preponderance of affected females may reflect differential exposure to toxins through foraging or sexlinked differences in toxin metabolism. For instance, female pipefish eat more and forage differently than males (Steffe et al. 1989), and gender differences exist in metabolism of xenobiotics (Bonate 1991).

The putative toxins isolated from the puffer livers all exhibited characteristics of small polar molecules $(<200 \mathrm{Da}) \cdot{ }^{13} \mathrm{C}$ chemical shifts of the most abundant toxic fraction indicated 2 methyl groups $(\delta 11.0,13.2)$, a methine ( $\delta 35.8)$, a methylene $(\delta 25.4)$, and a downfield methine consistent with that of an $\alpha$ carbon of an amino acid $(\delta 57.4)$. The proton attached to this $\alpha$ carbon $(\delta$ 3.88) showed a heteronuclear multiple bond correlation (HMBC) to a carbonyl $(\delta 171.9)$ that was not readily observed in the ${ }^{13} \mathrm{C}$ NMR experiment; however, further examination established an isoleucine moiety. A second spin system consisted of a downfield methylene $(\delta 66.1)$ and an oxymethine $(\delta 74.4)$ and supported an isoleucine modified by an aminodiol functionality. The mass spectrum of the major toxic fraction demonstrated the predicted MW of 190 as well as a loss of water at $172 \mathrm{Da}$, providing a strong corroboration of the predicted structure (Fig. S1). There were a fair number of inseparable (by HPLC) analogs apparent in the NMR spectra. 
However, NMR and MS analysis could only be taken so far due to the very small sample size $(<35 \mu \mathrm{g})$ of each toxic fraction and limited amounts of starting material (puffer livers) adding to the challenge of specific structural determination. However, the ${ }^{1} \mathrm{H}$ and ${ }^{13} \mathrm{C}$ spectra of all of the toxic analogs were similar in size and in structural backbone (Fig. 6, Fig. S1). The analogs appear to have stereochemical alterations and double bond additions, and some demonstrate the loss of hydroxyl groups. These analogs were only found in bioactive liver extracts and were either non-existent or below detection in livers testing inactive against our bioassays. The presence of the various analogs may, of course, represent liver degradation products from a larger parent toxin. However, such a parent was not observed in our extracts or defined by NMR/MS in active fractions. Although STX (Nakamura et al. 1984) and TTX (Yotsu-Yamashita 2001) have been seen in puffers elsewhere, we observed only minimal concentrations of TTX and no STX in our samples and therefore ruled out these toxins as a cause of the mortality.

Predominant strandings in Maui and Oahu likely reflect human population densities and reporting bias rather than transport of fish by currents and eddies formed by the Hawaiian islands (Chopra 1973). The marked decline of A. meleagris from fish counts in western Hawaii suggests this mortality might have had some detectable demographic effects. A. meleagris comprised a minority of fish observed or recovered for necropsy; however, they were a majority of tetraodontids seen in field population surveys. A. meleagris that were observed underwater were typically wedged between rocks in the benthos, so they were likely less visible and not easily recovered compared to A. hispidus that were mostly found floating and visible to the public. Thus, a major limitation of this study is uncertainty of just how detectable sick or dying A. meleagris or Diodon hystrix were relative to $A$. hispidus. Population declines of $A$. meleagris started a year before the 2010 epizootic, so declines could have been caused by factors other than marine toxins. However, the lesions we saw in $A$. meleagris were similar to those of $A$. hispidus, suggesting that at least in 2010, polar marine toxins played a role in declines of $A$. meleagris. Clinical behavior of sick fish and their impact on detectability should figure into estimates of demographic impacts of fish kills. Our high rate of detection for $A$. hispidus may have also been the result of their toxicity (Yotsu-Yamashita 2001) discouraging opportunistic predators that generally avoid pufferfish (Brainerd 1994). The low numbers of $A$. hispidus and $D$. hystrix in field surveys from western Hawaii precluded our detection of declines in these species; however, divers and fishermen have noted reduced numbers of $A$. hispidus since the 2010 epizootic.

Given that the liver was the most commonly affected organ and is the major filter for blood originating from the gastrointestinal tract, we suspect toxins were ingested and absorbed into the liver where they caused pathology. Crustacea were the most common item seen in the GI tract of affected puffers, so ingestion of toxic crustaceans may have been responsible. However, crustaceans with their durable hard parts that persist in the gut likely biased our enumeration. More systematic studies show that A. hispidus in Hawaii mainly feed on tunicates, echinoids, and ophiuroids, with crustaceans comprising a minority of their diet (Hobson 1974), whereas in the equatorial North Pacific, they feed on sponges, corals, and algae such as Lyngbya, Centroceras, and Caulerpa (Dawson et al. 1955). Tunicates (Watters \& van den Brenk 1993) and Lyngbya (Foss et al. 2012) can produce a variety of polar and non-polar toxins, none of which were seen in our analyses.

The source of the toxin is unknown. Some marine toxins originate from dinoflagellates or diatoms and are bioaccumulated through prey (Whittle \& Gallacher 2000) or affect fish directly by causing gill irritation (Sakai et al. 1986). In small oceanic islands, harmful algal blooms are uncommon (Hallegraeff 1993) or occur in limited geographic areas (Satoru \& Laws 1989), and no evident blooms were reported during the time of the epizootic. However, levels of coastal chl $a$ were higher than average in 2010 during the months preceding the epizootic, suggesting that conditions might have been favorable for a bloom of algae, and blooms of particularly small organisms such as picoplankton could have been missed. The chl $a$ and SST patterns presented here should serve as a useful comparison baseline for future epizootics of puffers.

The only other comparable unusual mortalities of Tetraodontidae include a die-off of Diodon Maculatus in Ceylon attributed to ectoparasitic copepods (Kirtisinghe 1934) and a die-off of D. halacanthus in Japan attributed to seasonal ocean currents (Nishimura 1958a,b,c). Although we present compelling data that the Hawaii puffer die-off was a natural toxic event, we were unable to confirm experimentally that the polar toxin caused the mortality nor did we have sufficient material to detect possible parent toxins in stomach contents. This study highlights the difficulty in characterizing unknown highly polar toxins which in this instance required a $5 \mathrm{yr}$ effort of method 
development that consumed most of the frozen liver samples we had collected. That highly polar toxins are problematic to purify and detect is reflected in the marine toxin literature where they comprise a minority $(<5 \%)$ of documented natural toxins (Blunt et al. 2012). If we are to truly understand the role of marine toxins in wildlife mortalities (and human health), we will need a more efficient way to identify novel compounds (Gaudencio \& Pereira 2015).

Acknowledgements. We thank the many members of the public and Eyes of the Reef volunteers who reported dead or dying puffers; Dr. Matthew J. Bertin at Biosortia Pharmaceuticals for analysis of NMR spectra; and Dr. Jim Driver of the University of Montana for electron microscopy services. Amy Wolf facilitated donation of columns and reagents for toxinology. Don McLeish kindly provided the photos for Fig. 1. Keith Loftin reviewed earlier versions of this manuscript. Mention of products or trade names does not imply endorsement by the US Government. Data from this study are available from the USGS, who funded the study, at the following site: http://dx.doi.org/10.5066/F7SQ8XM8.

\section{LITERATURE CITED}

Aldenhoven JM (1986) Local variation in mortality rates and life-expectancy estimates of the coral-reef fish Centropyge bicolor (Pisces: Pomacanthidae). Mar Biol 92: 237-244

Bennett BA (1985) A mass mortality of fish associated with low salinity conditions in the Bot River estuary. Trans R Soc S Afr 45:437-447

Blunt JW, Copp BR, Keyzers RA, Munroa MHG, Prinsep MR (2012) Marine natural products. Nat Prod Rep 29:144-222

Bohnsack JA (1983) Resiliency of reef fish communities in the Florida Keys following a January 1977 hypothermal fish kill. Environ Biol Fishes 9:41-53

Bonate PL (1991) Gender-related differences in xenobiotic metabolism. J Clin Pharmacol 31:684-690

Brainerd EL (1994) Pufferfish inflation: functional morphology of postcranial structures in Diodon holocanthus (Tetraodontiformes). J Morphol 220:243-261

Brockes JP, Kumar A (2008) Comparative aspects of animal regeneration. Annu Rev Cell Dev Biol 24:525-549

Brusle J (1995) The impact of harmful algal blooms on finfish: occurrence of fish kills, pathology, toxicological mechanisms, ecological and economic impacts. A review. In: IFREMER (ed) Repere Ocean, Book 10. IFREMER, Plouzane

Chanet B, Guintard C, Lecointre G (2014) The gas bladder of puffers and porcupinefishes (Acanthomorpha: Tetraodontiformes): phylogenetic interpretations. J Morphol 275:894-901

Chopra KP (1973) Atmospheric and oceanic flow problems introduced by islands. Adv Geophys 16:297-421

* Clauss TM, Dove ADM, Arnold JE (2008) Hematologic disorders of fish. Vet Clin North Am Exot Anim Pract 11: 445-462

Dawson EY, Aleem AA, Halstead BW (1955) Marine algae from Palmyra Island with special reference to the feeding habits and toxicology of reef fishes. Allan Hancock Foun- dation Publications, Book 17. The University Of Southern California Press, Los Angeles, CA

*Fänge R (1983) Gas exchange in fish swim bladder. Rev Physiol Biochem Pharmacol 97:111-158

*Foss AJ, Phlips EJ, Aubel MT, Szabo NJ (2012) Investigation of extraction and analysis techniques for Lyngbya wollei derived paralytic shellfish toxins. Toxicon 60:1148-1158

*Gaudencio SP, Pereira F (2015) Dereplication: racing to speed up the natural products discovery process. Nat Prod Rep 32:779-810

Glibert PM, Landsberg JH, Evans JJ, Al-Sarawi MA and others (2002) A fish kill of massive proportion in Kuwait Bay, Arabian Gulf, 2001: the roles of bacterial disease, harmful algae, and eutrophication. Harmful Algae 1:215-231

Hallegraeff GM (1993) A review of harmful algal blooms and their apparent global increase. Phycologia 32:79-99

*Helfrich P (1963) Fish poisoning in Hawaii. Hawaii Med J 22:361-372

Hobson ES (1974) Feeding relationships of teleostean fishes on coral reefs in Kona, Hawaii. Fish Bull 72:915-1031

Jain NC (1986) The erythrocyte: its morphology, metabolism, and survival. In: Jain NC (ed) Schalm's veterinary hematology. Lea \& Febiger, Philadelphia, PA, p 527-562

Katalay S, Parlak H (2004) The effects of pollution on haematological parameters of black goby (Gobius niger L., 1758) in Foça and Aliağa Bays. EU J Fish Aquat Sci 21: 113-117

Kirtisinghe P (1934) Parasitic infection of porcupine fish. Nature 133:142

* La VT, Cooke SJ (2011) Advancing the science and practice of fish kill investigations. Rev Fish Sci 19:21-33

* Le Cren ED (1951) The length-weight relationship and seasonal cycle in gonad weight and condition in the perch (Perca fluviatilis). J Anim Ecol 20:201-219

Letourneur Y, Kulbicki M, Labrosse P (1998) Length-weight relationships of fish from the lagoon of New Caledonia. An update. Naga (ICLARM Q J) 16:39-46

*Mallatt J (1985) Fish gill structural changes induced by toxicants and other irritants: a statistical review. Can J Fish Aquat Sci 42:630-648

McDowell E, Trump B (1976) Histological fixatives for diagnostic light and electron microscopy. Arch Pathol Lab Med 100:405-414

Moore MK, Work TM, Balazs GH, Docherty DE (1997) Preparation, cryopreservation, and growth of cells prepared from the green turtle (Chelonia mydas). Methods Cell Sci 19:161-168

Nakamura M, Oshima Y, Yasumoto T (1984) Occurrence of saxitoxin in puffer fish. Toxicon 22:381-385

Nishimura S (1958a) Mass stranding of porcupine puffer along the coasts of the Tsushima current region of the Japan archipelago - I. Occurrence of the mass stranding by regions (1). J Oceanogr Soc Jpn 14:53-58

Nishimura S (1958b) Mass stranding of porcupine puffer along the coasts of the Tsushima current region of the Japan archipelago - II. Occurrence of the mass stranding by regions (2). J Oceanogr Soc Jpn 14:59-63

Nishimura S (1958c) Mass stranding of porcupine puffer along the coasts of the Tsushima current region of the Japan archipelago - IV. A hypothesis for the mechanism of the mass stranding. J Oceanogr Soc Jpn 14:109-115

OIE (World Organisation for Animal Health) (2006) Manual of diagnostic tests for aquatic animals. OIE, Paris. Available at www.oie.int/doc/en_document.php?numrec= 3667303 
Pierce RH, Kirkpatrick GJ (2001) Innovative techniques for harmful algal toxin analysis. Environ Toxicol Chem 20: 107-114

Pinheiro HT, Gasparini JO, Joyeux J (2010) Reef fish mass mortality event in an isolated island off Brazil, with notes on recent similar events at Ascension, St Helena and Maldives. Mar Biodivers Rec 3:1-4

R Development Core Team (2011) R: a language and environment for statistical computing. R Foundation for Statistical Computing, Vienna. www.R-project.org

Sakai T, Yamamoto K, Endo M, Kuroki A, Kumanda K, Takeda K, Aramaki T (1986) Changes in the gill carbonic anhydrase activity of fish exposed to Chattonella marina red tide, with special reference to the mortality. Bull Jpn Soc Sci Fish 52:1351-1354

Satoru T, Laws EA (1989) Periodic blooms of the silicoflagellate, Dictyocha perlaevis in the subtropical inlet, Kaneohe Bay, Hawaii, USA. In: Okaichi T, Anderson DM, Nemoto $\mathrm{T}$ (eds) Red tides: biology, environmental science. Elsevier, Amsterdam, p 69-72

Scheffer M, Bascompte J, Brock WA, Brovkin V and others (2009) Early-warning signals for critical transitions. Nature 461:53-59

Steffe AS, Westoby M, Bell JD (1989) Habitat selection and diet in two species of pipefish from seagrass: sex differences. Mar Ecol Prog Ser 55:23-30

Thronson A, Quigg A (2008) Fifty-five years of fish kills in

Editorial responsibility: Bernd Sures, Essen, Germany coastal Texas. Estuaries Coasts 31:802-813

* Velmurugan B, Selvanayagam M, Cengiz EI, Unlu E (2009) Histopathological changes in the gill and liver tissues of freshwater fish, Cirrhinus mrigala exposed to dichlorvos. Braz Arch Biol Technol 52:1291-1296

WWatters DJ, van den Brenk AL (1993) Toxins from ascidians. Toxicon 31:1349-1372

* Whittington RJ, Jones JB, Hine PM, Hyatt AD (1997) Epizootic mortality in the pilchard Sardinops sagax neopichardus in Australia and New Zealand in 1995. I. Pathology and epizootiology. Dis Aquat Org 28:1-15

*Whittle K, Gallacher S (2000) Marine toxins. Br Med Bull 56: 236-253

*Williams ID, Walsh WJ, Claisse JT, Tissot BN, Stamoulis KA (2009) Impacts of a Hawaiian marine protected area network on the abundance and fishery sustainability of the yellow tang, Zebrasoma flavescens. Biol Conserv 142:1066-1073

Wolf JC, Baumgartner WA, Blazer VS, Camus AC and others (2015) Nonlesions, misdiagnoses, missed diagnoses, and other interpretive challenges in fish histopathology studies: a guide for investigators, authors, reviewers, and readers. Toxicol Pathol 43:297-325

Yamamoto K (1988) Contraction of spleen in exercised freshwater teleost. Comp Biochem Physiol A Physiol 89:65-66

* Yotsu-Yamashita M (2001) Chemistry of puffer fish toxins. J Toxicol Toxin Rev 20:51-66

Submitted: October 12, 2016; Accepted: December 12, 2016 Proofs received from author(s): February 28, 2017 